\title{
Contribution to the improvement of the detection of defects located in heritage by stimulated infrared thermography associated with a spatial reassignment of the color dynamics of thermograms
}

\author{
by K. Mouhoubi**, K. Dieng*, C. Fomena*, H. Feddini*, A. Salami*,
} J.M. Vallet ${ }^{* * *}$, J.L. Bodnar*

* ITheMM, Université de Reims Champagne Ardenne, UFR Sciences Exactes et Naturelles, Campus du Moulin de la Housse - BP 1039, 51687 Reims Cedex 2, France

** SATT-Nord, 4 Boulevard de la Paix, 51100 Reims, France

*** Centre Interdisciplinaire de Conservation et Restauration du Patrimoine (CICRP), 21 rue Guibal, 13003 Marseille, France

\begin{abstract}
In the context of the conservation of works of art from the cultural heritage, stimulated infrared thermography allows the non-destructive detection of the presence of defects invisible to the naked eye. However, images obtained with a thermal camera are sometimes difficult to interpret directly. Indeed, optical parasitic effects due to absorptivity variations in surface or excitation inhomogeneities can lead to detection artifacts. To reduce these effects, it's possible to use postprocessing algorithms. The work we present here follows this framework. We show first theoretically, then experimentally, that a spatial re-allocation of the colorimetric dynamics of the obtained image makes it possible to significantly reduce these parasitic radiative effects. The theoretical study is based on a simulation, using finite element methods, the experimental part was developed on a plaster block containing 32 defects and a multicoloured paint layer.
\end{abstract}

\section{Introduction}

Stimulated infrared thermography applied to the preservation of heritage allows the non-destructive detection of defects invisible to the naked eye [1-72]. However, images obtained by thermography are sometimes difficult to interpret: optically-induced parasitic effects resulting from variations in surface radiative properties, or excitation inhomogeneities, can lead to detection artifacts. Researchers suggest the use of post-processing algorithms to remedy these difficulties. The work we present here falls within this framework. In the latter, we study the possibilities of a spatial re-allocation of the colorimetric dynamics of thermograms. The idea is a total re-allocation of the colorimetric dynamics for each color of the pictorial layer.

Our study is based on a theoretical study and an experimental study.

The theoretical study is conducted using finite element modeling of the photothermal experiment developed on a sample containing six defects and a bicolour paint layer.

The experimental study is conducted using the THERMO-ART system associated with the IR EXPLORER software package. The experimentally analysed sample is a plaster block containing 32 defects and a multicoloured paint layer.

The results obtained, at both theoretical and experimental levels, clearly show that a spatial redistribution of the colorimetric dynamics of the image obtained allows a significant reduction of the parasitic radiative effects and therefore a better detection of defects.

\section{Theoretical study}

The theoretical study we have developed is based on a modeling of the pulsed photothermal experiment applied to a sample containing six defects and a bicolor pictorial layer.

This theoretical sample is presented in Figures 1 and 2. It is a rectangular block of plaster (as its thermophysical properties are very close to those of a mural). Its geometrical dimensions are a length of $160 \mathrm{~mm}$, a width of $120 \mathrm{~mm}$ and a thickness of $20 \mathrm{~mm}$. Its thermophysical properties are a thermal conductivity of $0.4 \mathrm{~W} / \mathrm{mK}$, a density of $1100 \mathrm{~kg} / \mathrm{m} 3$, a heat capacity of $830 \mathrm{~J} / \mathrm{kg} \mathrm{K}$, i.e. a thermal diffusivity of $4.3810-7 \mathrm{~m} 2 / \mathrm{s}$. In order to simulate the presence of displacements, we considered six air gaps placed in this sample. We considered that these defects were parallelepiped and had the same geometrical dimensions. Their length and width are equal to $20 \mathrm{~mm}$. Their thickness is equal to $4 \mathrm{~mm}$. Their depths vary from $2 \mathrm{~mm}$ to $12 \mathrm{~mm}$ in steps of $2 \mathrm{~mm}$ (the sample is scanned from top to bottom and then from left to right). The thermophysical properties taken into account for these defects are those of air at $20^{\circ} \mathrm{C}$ : a thermal conductivity of 0.026 $\mathrm{W} / \mathrm{mK}$, a density of $1.17 \mathrm{~kg} / \mathrm{m} 3$, a heat capacity of $1006 \mathrm{~J} / \mathrm{kg} \mathrm{K}$ or a thermal diffusivity of $2.2210-5 \mathrm{~m} 2 / \mathrm{s}$. Finally, in order to simulate the optical effects induced by the paint layer, we divided the surface of our sample into two parts. The first covers the defects located at $4 \mathrm{~mm}, 8 \mathrm{~mm}$ and $12 \mathrm{~mm}$ depth. The second part covers the defects located at $2 \mathrm{~mm}, 6 \mathrm{~mm}$ and $10 \mathrm{~mm}$ deep. 
On the other hand, we have imposed on the second one a flow 1.5 times more energy than on the first one. The type of excitation signal considered is a crenel. Its duration is equal to 2 seconds. The analysis time is 200 seconds. The acquisition frequency is equal to $1 \mathrm{~Hz}$. The energy power set is $1500 \mathrm{~W}$. We considered, a model without losses. Finally, the resolution of the differential system associated with the problem was done using the finite element method.

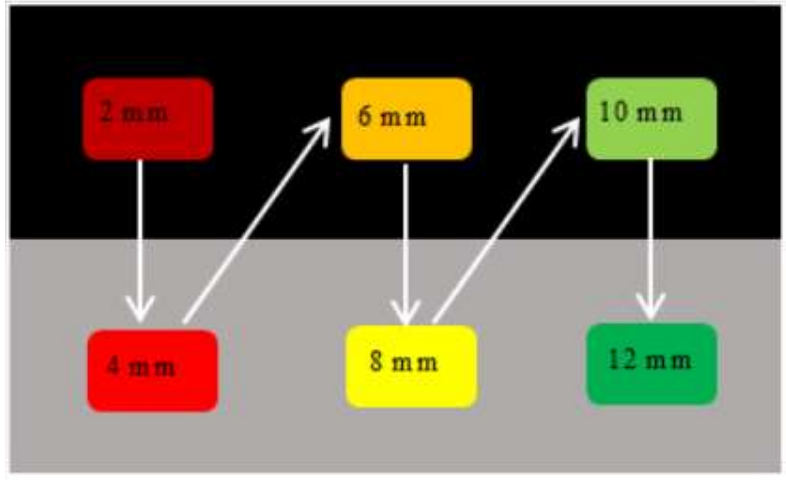

Fig. 1. The theoretically studied sample (top view)

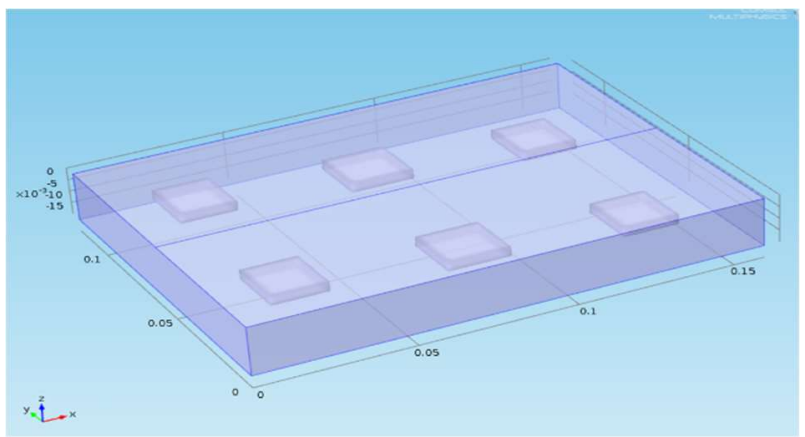

Fig. 2. The theoretically studied sample (side view)

Figure 3 shows an example of a theoretical thermogram obtained. This is the instant of observation $t=200 \mathrm{~s}$ after the end of the excitation. It first clearly shows larger photothermal signatures at the defects, which allows their detection. $\mathrm{He}$ then shows that these signatures are all the weaker as the depth of the defects increases. Finally and most importantly, it shows the presence of two bands, blue and red, due to the inhomogeneity of the energy deposit. The latter clearly disturbs the detection of the defects.

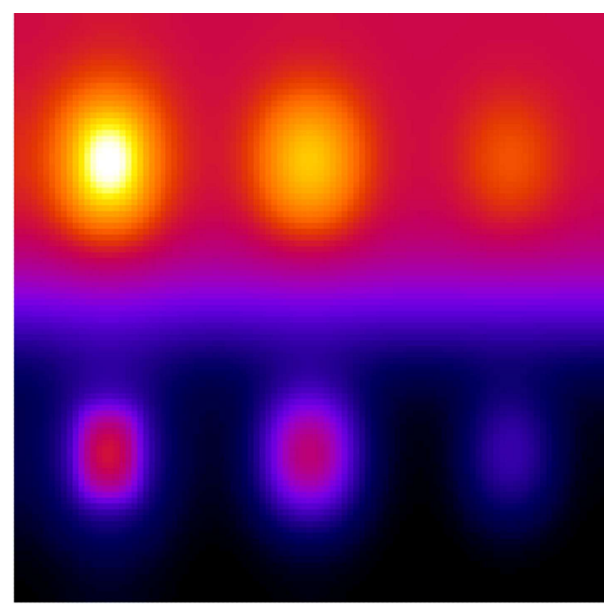

Fig. 3. Example of a theoretical thermogram obtained ( $t=200 \mathrm{~s})$ 
In order to reduce this disturbing effect of the paint layer, we proceeded to a spatial reallocation of the color dynamics of the thermograms. For this, we considered the visible image of the sample surface. The latter was then spatially cut out according to the colour of the pictorial layer. In our case study, this led to the definition of two spatial zones (figure 4).

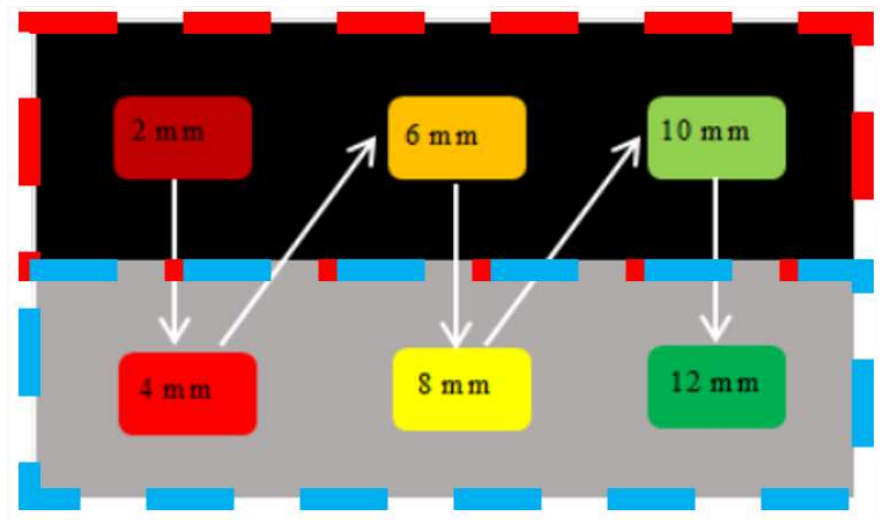

Fig. 4. The two areas of analysis chosen

The data cube of the thermographic film was then cut successively according to these two areas. For each of these areas, the entire dynamic range of the digital coding was reallocated. An example of the result obtained is shown in Fig. 5. This is the spatial reallocation of the thermogram colour dynamics shown in Fig. 3. This figure clearly shows the interest of this post-processing technique. Indeed, photothermal signatures appear more important at the position of these defects. These signatures are always correlated with the depth of these defects. It shows finally and above all, the notable reduction of the disturbing effect of the pictorial layer on the detection of defects.

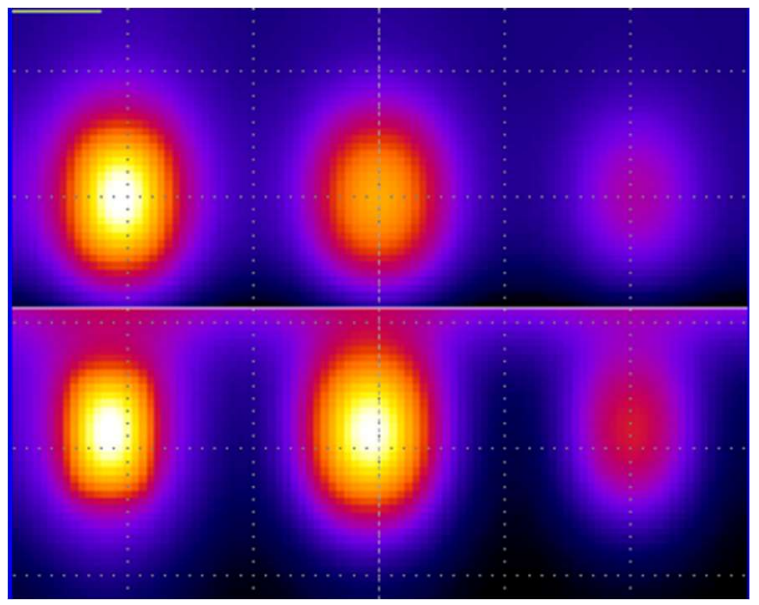

Fig. 5. Example of theoretical thermogram obtained after post-treatment ( $t=200 \mathrm{~s})$

\section{Experimental study}

As the results obtained during the theoretical study were very encouraging, we proceeded in a second stage to an experimental study.

The sample studied is a block of plaster (because its properties are close to those of a mural painting) containing 32 defects and a multicoloured pictorial layer (figures 6 and 7). Its dimensions are a width of $68 \mathrm{~cm}$, a height of $50 \mathrm{~cm}$ and a thickness of $5 \mathrm{~cm}$. The back side of this sample was manufactured in order to introduce 32 defects. These are $2 \mathrm{~mm}$ thick polystyrene inserts positioned $5 \mathrm{~mm}$ deep (pictorial layer). The diameter of these defects is $30 \mathrm{~mm}$.

The paint layer includes 20 different colour space zones. 10 areas have an approximate size of $16 \mathrm{~cm}{ }^{*} 16 \mathrm{~cm}$. The other 10 areas have a dimension of roughly $8 \mathrm{~cm}{ }^{*} 6 \mathrm{~cm}$.

Defects are evenly distributed throughout the sample in order to cover the total surface area of the sample. 


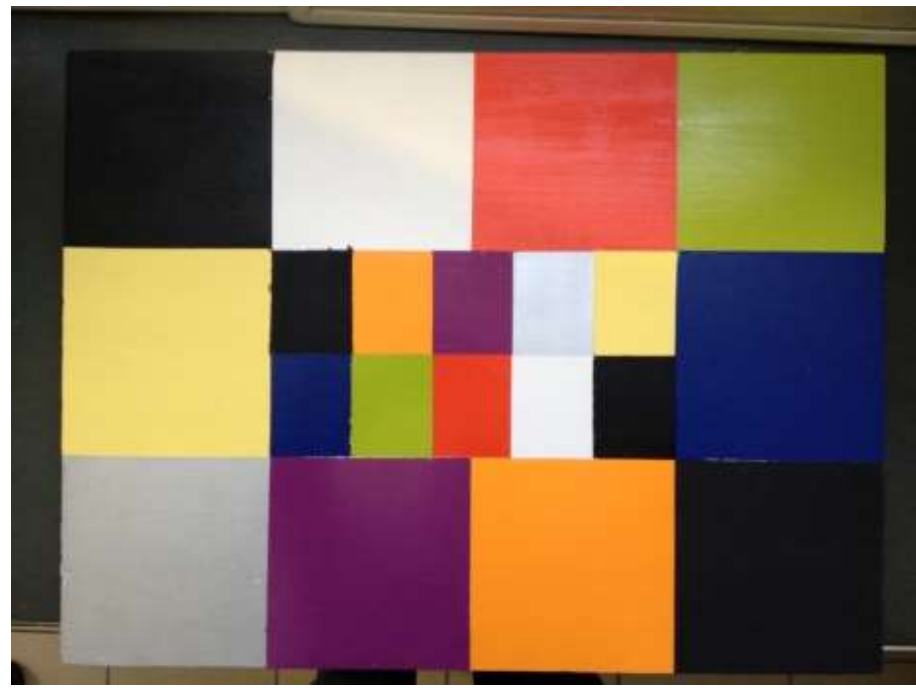

Fig. 6. The sample studied (front view)

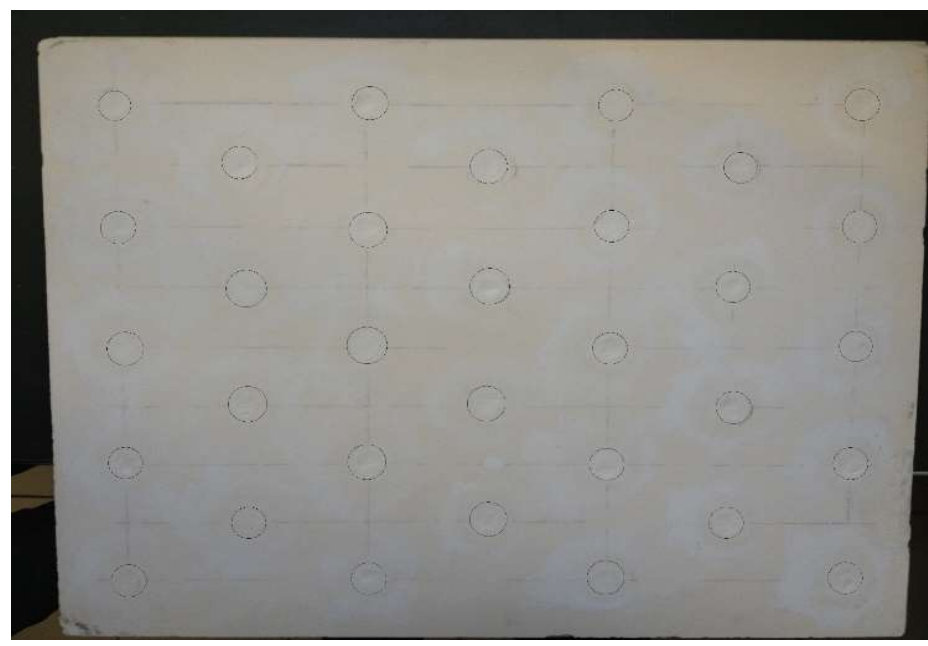

Fig. 7. The sample studied (rear view)

The experimental device used is the "THERMOART" system (Figure 8). This device is divided into three parts. The first part is the excitation source. Among all the options offered by the "THERMOART" system, we have chosen to use a pair of 500-watt halogen lamps. They are placed on either side of the infrared acquisition system and about $50 \mathrm{~cm}$ from the sample being studied. The excitation angle is about 45 degrees to the normal direction of the test sample.

The second part of the "THERMOART" system is the infrared collection optics. This consists of an infrared thermography camera type FLIR SC 655. The reason for choosing a bolometer camera is that wall paintings are thermally slow materials. It is also explained by the moderate cost of the instrumentation. This camera is also placed at about $50 \mathrm{~cm}$ from the sample under study (between the halogen lamps). Note that the optics of the camera has an optical aperture of 50 degrees, in order to observe the entire sample.

The last part of the "THERMOART" system is a computerized data acquisition and processing system. For the acquisition, we used the FLIR Researcher 2.10 software package. As regards data processing, we used the "IREXPLORER" software package developed at the ITHEMM laboratory and in the process of technology transfer (URCA / CICRP / SATT nord, figure 10). The spatial reallocation function of the software's colorimetric dynamics was used. 


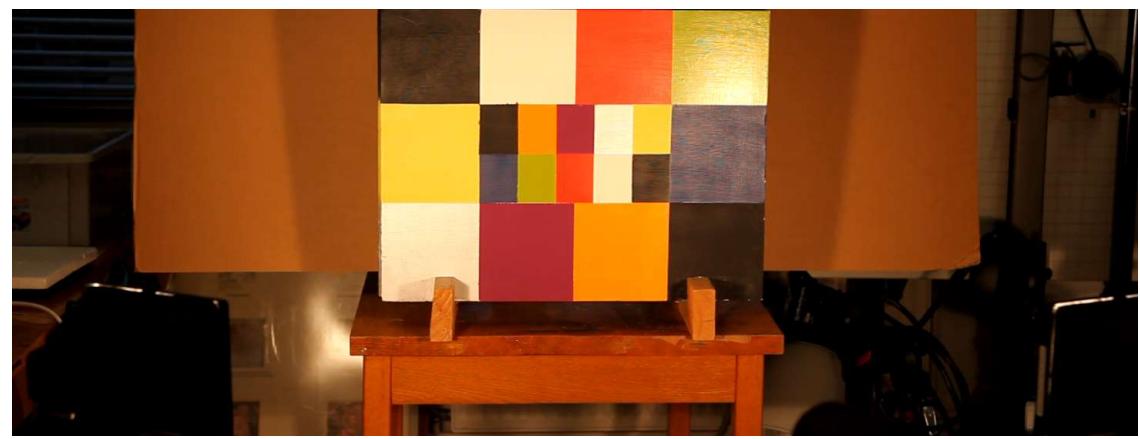

Fig. 8. The "THERMOART" system used

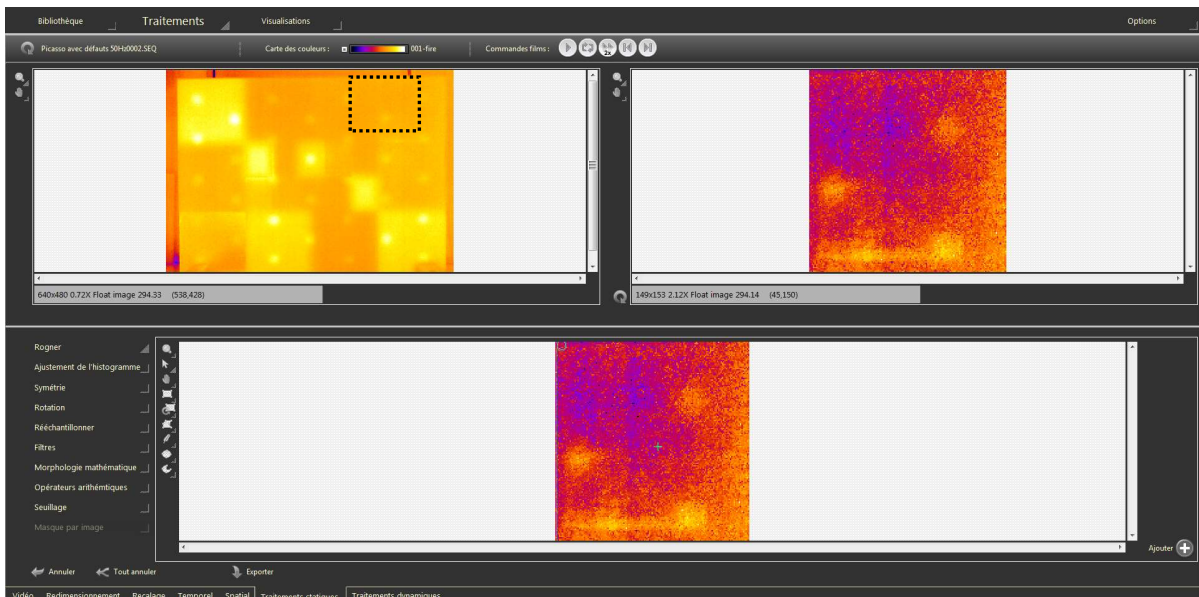

Fig. 9. The "IREXPLORER" software package used

(Treatment of the upper right green square of the multicolour sample analysed)

Finally, the excitation and analysis conditions selected are: an excitation time of 60 seconds and a total analysis time of 180 seconds.

The best experimental thermogram obtained from this analysis is shown in Figure 10. This figure shows that the method allows the detection, with more or less contrast, of almost all the defects located in the sample studied. It also shows that the parasitic effects induced by the pictorial layer perturb the detection of defects because they significantly affect the contrast.

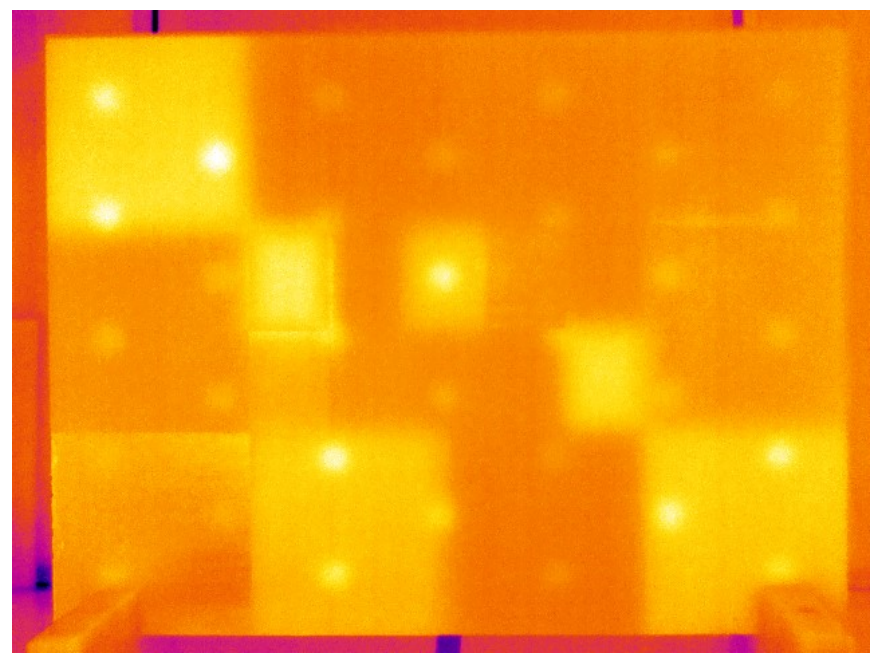

Fig. 10. raw experimental thermogram obtained during the analysis of the multicoloured plaster block. 
In order to try to improve the detection of these defects, we proceeded to a spatial reallocation of the colorimetric dynamics of the previous thermogram. For this we proceeded as a theoretical study. The areas of spaces considered are the different rectangles of colours which were treated one after the other. We have successively attributed to them all the dynamics allowed by the digitization and we have reconstructed the synthetic thermogram presented on figure 11 . This figure clearly shows that this post-processing of the data allows a notable improvement in the contrast of the photothermal signature of the defects and thus a better detection of the latter.

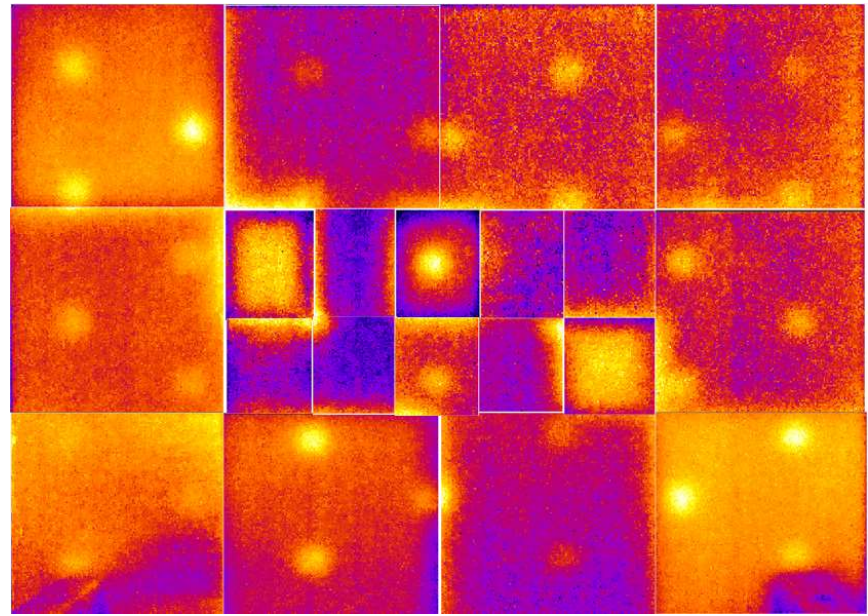

Fig. 11. result obtained after spatial reallocation of the colorimetric dynamics of the thermogram resulting from the analysis of the multicolored plaster block.

\section{Conclusion}

The work presented in this study aimed to approach the possibilities of a particular signal processing: the spatial reallocation of the colorimetric dynamics of experimental thermograms in order to improve the detection of defects located in heritage wall paintings. It is more particularly the parasitic effects induced by the pictorial layer (multicoloured by nature and therefore not absorbing the exciter flux in the same way) that we wish to reduce.

With the help of two theoretical and experimental studies, we have clearly shown that this numerical tool allows a notable increase in the photothermal contrast located in the plumb line of the defects studied and a significant improvement in the possibilities of detection of the latter.

These studies carried out in laboratories on representative martyr samples now need to be developed for in situ analysis of works of art from the cultural heritage. Studies in this direction are under way.

\section{REFERENCES}

[1] J.C. Candoré, G. Szatanik, J.L Bodnar, V. Detalle, P. Grossel : Infra-red photothermal thermography: A tool of assistance for the restoration of murals paintings? Proc of QIRT2006, Padova (Italie), 28 - 30 juin 2006.

[2] Ibarra-Castanedo, C., Sfarra, S., Ambrosini, D., Paoletti, D., Bendada, A., Maldague, X.: 'Subsurface defect characterization in artworks by quantitative pulsed phase thermography and holographic interferometry', QIRT Journal, 2008, 5(2), pp. 131-149.

[3] J.C. Candoré, J.L Bodnar, V. Detalle, P. Grossel : Non destructive testing of works of art by stimulated infrared thermography. Proc of QIRT 2008, Cracovie (Pologne), 2-5 juillet 2008.

[4] J.C. Candoré, J.L Bodnar, F. Depasse, V. Detalle, P. Grossel : Approach of the characterization of delamination in mural paintings. Proc of QIRT 2008, Cracovie (Pologne), 2-5 juillet 2008.

[5] J.C. Candoré, J.L. Bodnar, A. Szeflinski, L. Ibos: Helps with the thermal diagnosis of the building : Detection of defects of insulation by stimulated infra-red thermography. Proc of QIRT 2008, Cracovie (Pologne), 2-5 juillet 2008.

[6] J.C. Candoré, J.L Bodnar, V. Detalle, P. Grossel : Non destructive testing of mural paintings, in situ, by infrared photothermal radiometry, Proc of SMW08, Florence ( Italie), 27-29 octobre 2008.

[7] J.C. Candoré, J.L Bodnar, V. Detalle, P. Grossel: Non destructive testing in situ, of works of art by stimulated infrared thermography. Proc of the 15th International Conference on Photoacoustic and Photothermal Phenomena, Leuven (Belgique), 19-23 July 2009.

[8] J.C. Candoré, J.L Bodnar, V. Detalle, P. Grossel : Approach of the measurement of thermal diffusivity of mural painting by front face photothermal radiometry. Proc of the 15th International Conference on Photoacoustic and Photothermal Phenomena, Leuven (Belgique), 19-23 July 2009. 
[9] Ibarra-Castanedo, C., Sfarra, S., Ambrosini, D., Paoletti, D., Bendada, A., Maldague, X.: 'Diagnostics of panel paintings using holographic interferometry and pulsed thermography', QIRT Journal, 2010, 7(1), pp. 85-114.

[10] J.C. Candoré, J.L Bodnar, V. Detalle, P. Grossel: Non destructive testing in situ, of works of art by stimulated infra-red thermography, Journal of physics, 2010, 214, 012068.

[11] J.-M. Vallet, A. Sinigaglia, N. Le Van, B. Gandini, P.-A. Gatier, V. Detalle, J.-L. Bodnar, L. de Luca : Conservation des fresques romaines provenant de la villa de P. Fannius Synistor à Boscoreale et exposées à la Villa Kérylos (France) : Démarche, étude préalable et travaux de restauration. Proc du colloque « Les fresques romaines de Boscoreale : perspectives actuelles », Mariemont (Belgique), 21-23 avril 2010.

[12] J.C. Candoré, J.L Bodnar, V. Detalle, P. Grossel : Assistance to the restoration of historical frescoes by stimulated infrared thermography, Proc of QIRT 2010, Quebec (Canada), 27 - 30 juillet 2010.

[13] V. Detalle, S. Duchêne, V. Verges-Belmin, J.M. Vallet, J.L Bodnar : Application of laser in conservation and restoration of historical building, Proc of SPIE 2010, Brussels (Belgique), 12 - 16 avril 2010.

[14] Sfarra, S., Theodorakeas, P., Ibarra-Castanedo, C., Avdelidis, N.P., Paoletti, A., Paoletti, D., Hrissagis, K., Bendada, A., Koui, M., Maldague, X.: 'Importance of integrated results of different non-destructive techniques in order to evaluate defects in panel paintings: the contribution of infrared, optical and ultrasonic techniques'. Proc. of SPI - The International Society for Optical Engineering - O3A: Optics for Arts, Architecture, and Archaeology III, vol. 8084, Munich, Germany, October 2011.

[15] J.L Bodnar, J.L. Nicolas, K. Mouhoubi, J.C. Candore, V. Detalle : Characterization of an inclusion of plastazote located in an academic fresco by photothermal thermography, Proc of ICPPP 2011, Yucatan (Mexique), 27 nov -1 dec 2011.

[16] J.L. Bodnar, K. Mouhoubi, G. Szatanik-Perrier, J.M. Vallet, V. Detalle: Photothermal thermography applied to the non-destructive testing of different types of works of art, Proc of ICPPP 2011, Yucatan (Mexique), 27 nov 1 dec 2011.

[17] Sfarra, S., Theodorakeas, P., Ibarra-Castanedo, C., Avdelidis, N.P., Paoletti, A., Paoletti, D., Hrissagis, K., Bendada, A., Koui, M., Maldague, X.: 'Evaluation of defects in panel paintings using infrared, optical and ultrasonic techniques', Insight: Non-destructive Testing and Condition Monitoring, 2012, 54(1), pp. 21-27.

[18] J.C. Candoré, J.J. Bodnar, V. Detalle, P. Grossel : Non-destructive testing of works of art by stimulated infrared thermography, European physical journal : Applied physics, 2012, vol 57, 21002

[19] J.C. Candoré, J.L. Bodnar, V. Detalle, P. Grossel : Characterization of defects situated in a fresco by stimulated infrared thermography, European physical journal : Applied physics, 2012, 57, 11002.

[20] J.L Bodnar, J.C Candoré, J.L. Nicolas, G. Szatanik, V. Detalle, J.M. Vallet: Stimulated infrared thermography applied to help restoring mural paintings, Journal of non-destructive testing and evaluation, 2012, vol 49, pp. 4046.

[21] J.L. Bodnar, K. Mouhoubi, G. Szatanik-Perrier, J.M. Vallet, V. Detalle : Photothermal thermography applied to the non-destructive testing of different types of works of art, International Journal of Thermophysics, 2012, vol 33, pp 1996-2000.

[22] J.L Bodnar, J.L. Nicolas, K. Mouhoubi, V. Detalle : Stimulated infrared thermography applied to thermophysical characterization of cultural heritage mural paintings, European physical journal : Applied physics, 2012, 60, 21003.

[23] Vrabie, V., Perrin, E., Bodnar, J.-L., Mouhoubi, K., Detalle, V.: 'Active IR thermography processing based on higher order statistics for non-destructive evaluation'. Proc. of 20th European Signal Processing Conference (EUSIPCO), Bucharest, Romania, August 2012, pp. 894-898.

[24] E. Bernikola, E. Tsiranidou, V. Tornari, V. Detalle, J.L. Bodnar : Mapping of defect structural micro-morphology in the documentation of conservation approaches, proc of EuroMed 2012, Lemosos (Chypre), 29 oct - 3 nov 2012.

[25] J.L Bodnar, J.J Metayer, K. Mouhoubi, V. Detalle : Non destructive testing of works of art by stimulated infrared thermography and terahertz analysis, Proc of QIRT 2012, Naples (Italie), $11-14$ juin 2012.

[26] J.L Bodnar, J.L. Nicolas, K. Mouhoubi, V. Detalle : Thermal diffusivity measurement of mural painting by simulated infra-red thermography, Proc of QIRT 2012, Naples (Italie), 11 - 14 juin 2012.

[27] Gavrilov, D., Maeva, E., Grube, O., Vodyanoy, I., Maev, R.: 'Experimental comparative study of the applicability of infrared techniques for non-destructive evaluation of paintings', Journal of the American Institute of Conservation, 2013, 52(1), pp. 48-60.

[28] J.L Bodnar, J.L. Nicolas, K. Mouhoubi, J.C. Candore, V. Detalle : Characterization of an inclusion of plastazote located in an academic fresco by photothermal thermography International Journal of Thermophysics, 2013, 34, pp 1633-1637.

[29] V. Tornari, E. Bernikola, E. Tsiranidou, K. Hatzigiannakis, M. Andrianakis, V. Detalle, J.L Bodnar : Micromapping of defect structural micro-morphology in the documentation of fresco wallpaintings, International Journal of Heritage in the Digital Era, vol 2, $\mathrm{n}^{\circ} 1,2013$, pp $1-23$.

[30] J.L. Bodnar, K. Mouhoubi, L. Di Pallo, V. Detalle, J.M. Vallet, T. Duvaut : Contribution to the improvement of heritage mural painting non-destructive testing by stimulated infrared thermography, European physical journal : Applied physics, 2013, 64, 11001

[31] S. Sfarra, J.L. Bodnar, D. Ambrosini, K. Mouhoubi, D. Paoletti : Edge detection combined with optical and infrared NDT techniques: an aid for wooden samples with complex surface and subsurface defects, proc of the 13th International Symposium on Nondestructive Characterization of Materials, Le Mans, 20 - 25 mai 2013. 
[32] E. Perrin, V. Vrabie, J.L. Bodnar, J.L. Nicolas, K. Mouhoubi, V. Detalle : Non destructive testing of works of art by stimulated infrared thermography associated to high orders statistics, proc of $3^{\text {rd }}$ International congress on the Engineering of the Industrial Risks, Reims, 3 - 5 juillet 2013.

[33] J.M. Vallet, V. Detalle, J.L. Bodnar, L. Di Luca, O. Guillon, B. Trichereau, K. Mouhoubi, N. Martin- Beaumont, D. Syvilay, D. Giovannacci, C. Stefani, G. Walker, D. Martos-Le Vif, P. Marron, F. De Banes Gardonne : Development of a NDT toolbox dedicated to the conservation of wall paintings: application to the frescoes chapel in the Benedictine Charterhouse of Villeneuve-lès-Avignon (France), Proc of Digital heritage 2013, Marseille, 28 oct -1 nov 2013.

[34] Gavrilov, D., Maeva, E., Maev, R.G.: 'Thermographic inspection in the service of art science: theory, methods and considerations', Insight: Non-Destructive Testing and Condition Monitoring, 2014, 56(3), pp. 131-136.

[35] K. Mouhoubi, J.-M. Vallet, V. Detalle, J.-L. Bodnar : Detection of hygroscopic salts before the apparition of degradation patterns: experimental approach on limestones using the stimulated infrared thermography, ICOMOS-ISCS International Conference 2014, Gongju (Korea), 20 - 23 mai 2014.

[36] K. Mouhoubi, S. Gomis, J.L. Bodnar, V. Detalle : Laser Contribution in the differentiation techniques pigment deposition in the murals, Lacona 2014, Sharjah (United Arab Emirates), 9-13 juin 2014.

[37] K. Mouhoubi, J.L Bodnar, J.L. Nicolas, E. Perrin, V. Vrabie, V. Detalle, J.M. Vallet : Non destructive testing of the works of art by stimulated infra-red thermography: Study of the contribution of SVD decomposition to the reduction of the optical effects induced by the pictorial layer, proc of QIRT 2014, Bordeaux, 7-11 juillet 2014.

[38] K. Mouhoubi, J.L Bodnar, J.L. Nicolas, V. Detalle, J.M. Vallet, T. Duvaut : Contribution to the local thermophysical characterization of murals paintings of the inheritance by stimulated infra-red thermography, proc of QIRT 2014, Bordeaux, 7-11 juillet 2014.

[39] K. Mouhoubi, J.L Bodnar, L. Ibos, V. Detalle, J.M. Vallet : Identification of frescoes among mural paintings of the inheritance by stimulated infrared thermography, proc of QIRT 2014, Bordeaux, 7-11 juillet 2014

[40] Bendada, A., Sfarra, S., Ibarra-Castanedo, C., Akhloufi, M., Caumes, J.-P., Pradere, C., Batsale, J.-C., Maldague, X.: 'Subsurface imaging for panel paintings inspection: a comparative study of the ultraviolet, the visible, the infrared and the terahertz spectra', Opto-electronics Review, 2015, 23(1), pp. 88-99.

[41] Sfarra, S., Theodorakes, P., Ibarra-Castanedo, C., Avdelidis, N.P., Ambrosini, D., Cheilakou, E., Paoletti, D., Koui, M., Bendada, A., Maldague, X.: 'How to retrieve information inherent to old restorations made on frescoes of particular artistic value using infrared vision?', International Journal of Thermophysics, 2015, 36(10-11), pp. 3051-3070.

[42] D. Giovannacci, V. Detalle, D. Martos-Levif , V. Tornari, E. Bernikola, K. Hatzigiannakis, K. Mouhoubi, J.-L. Bodnar, G.-C. Walker, J. Bowen, B. Jackson : « Case study of Sainte-Marie Chapel, Fontaine Chaalis (France): complementarity of different optical techniques », SPIE Optical Metrology, Optics for Arts, Architecture, and Archaeology V, Munich, Allemagne, 2015, 21-25 June

[43] C. Thomachot-Schneider, M. Gommeaux, P. Vazquez, N. Lelarge, A. Conreux, K. Mouhoubi, JL. Bodnar : Relationship between Na2SO4 concentration and thermal response of reconstituted stone in the laboratory and on site, World Multidisciplinary Earth Sciences Symposium, Prague, 7-11 sept 2015.

[44] P. Vázquez, C. Thomachot-Schneider, K. Mouhoubi, G. Fronteau, M. Gommeaux, D. Benavente, V. Barbin, JL. Bodnar : Infrared thermography as a tool to assess salt crystallization, World Multidisciplinary Earth Sciences Symposium, Prague, 7-11 sept 2015.

[45] M. Z. Ahmad, A. A. Khan, S. Mezghani, E. Perrin, K. Mouhoubi, J. L. Bodnar, V. Vrabie Wavelet subspace decomposition of thermal infrared images for defect detection in artworks, Infrared physics and technology, 77, 2016, $325-334$.

[46] K. Mouhoubi, J.L Bodnar, V. Detalle, J.M. Vallet : Stimulated infrared thermography applied to the local thermal characterization of fresco, QIRT 2016, Gdansk (Pologne) 4-8 juillet 2016

[47] P. Bison, A. Bortolin, G. Cadelano, G. Ferrarini, L. Finesso, K. Mouhoubi, J.L Bodnar : Thermographic survey of frescoes with different thermal stimuli: a PLS-based analysis, QIRT 2016, Gdansk (Pologne) 4-8 juillet 2016

[48] K. Mouhoubi, J.L Bodnar, V. Detalle, J.M. Vallet : Non-destructive testing of works of art by stimulated by infrared thermography: PPT interest, QIRT 2016, Gdansk (Pologne) 4-8 juillet 2016

[49] [50] K. Mouhoubi, J-L Bodnar, J.M. Vallet, V. Detalle, P. Vázquez, C. Thomachot-Schneider: Detection of NaCl located in mural painting by stimulated infrared thermography, QIRT 2016, Gdansk (Pologne) 4-8 juillet 2016

[50] K. Mouhoubi, C. Franzen, J.M. Vallet, V. Detalle, O. Guillon, J.L. Bodnar: Active IRT and theoretical simulation inputs for the voids determination in building material. Hughes, J., \& Howind, T. (Eds.) Science and Art: A Future for Stone: Proceedings of the 13th International Congress on the Deterioration and Conservation of Stone, Volume 1. Paisley: University of the West of Scotland, p 645, 2016

[51] D. Giovannacci, D. Brissaud, J.D. Mertz, K. Mouhoubi, and J.L. Bodnar: Non-Intrusive Tools To Detect Salts Contamination In Masonry: Case Study Of Fontaine-Chaalis Church. SPIE Optical metrology, Munich (Allemagne), 25 - 29 June 2017.

[52] K. Mouhoubi, JL. Bodnar, JM. Vallet, V. Detalle : Stimulated infrared thermography application to the Conservation of heritage wall paintings: interest of a Material and software combined approach, ICPPP 2017, Bilbao (Espagne), $17-21$ juillet 2017.

[53] K. Mouhoubi, JL. Bodnar, JM. Vallet, V. Detalle : Local estimation of thermal effusivity using stimulated infrared thermography, ICPPP 2017, Bilbao (Espagne), 17 - 21 juillet 2017. 
[54] K. Mouhoubi, J.L. Bodnar1, J.M. Vallet, V. Detalle : Follow-up of restoration of works of art of the patrimony by infrared thermography, AITA 2017, Quebec (Canada), 27 - 29 Septembre 2017.

[55] Laureti, S., Sfarra, S., Malekmohammadi, H., Burrascano, P., Hutchins, D.A., Senni, L., Silipigni, G., Maldague, X.P.V., Ricci, M.: 'The use of pulse-compression thermography for detecting defects in paintings', NDT\&E International, 2018, 98, pp. 147-154.

[56] K. Mouhoubi, JL. Bodnar, JM. Vallet, V. Detalle : Local estimation of thermal effusivity by stimulated infrared thermography, QIRT 2018, Berlin, 25 - 29 juin 2018.

[57] S. Eyssautier-Chuine, K. Mouhoubi, F. Reffuveille, J.L. Bodnar : Early detection of micro-organisms development on stone monuments thanks to the stimulated infrared thermography and singular value decomposition, QIRT 2018, Berlin, 25 - 29 juin 2018.

[58] K. Mouhoubi, J.L. Bodnar, J.M. Vallet, V. Detalle : Local estimation of thermal effusivity by stimulated infrared thermography, LACONA 12, 10-14 septembre 2018, Paris.

[59] J.M. Vallet, A. Pamart, O. Guillon, J.L. Bodnar, V. Detalle, A. Manuel, D. Martos levif, T. Messaoudi, K. Mouhoubi, L. Di luca : Improvement of the conservation diagnosis based on the merge of heterogeneous data and the use of an "in-situ toolbox": application to a wall painting case study, LACONA 12, 10-14 septembre 2018, Paris.

[60] Laureti, S., Malekmohammadi, H., Rizwan, M.K., Burrascano, P., Sfarra, S., Mostacci, M., Ricci, M.: 'Looking through paintings by combining hyper-spectral imaging and pulse-compression thermography', Sensors, 2019, 19(19), article number 4335.

[61] Laureti, S., Colantonio, C., Burrascano, P., Melis, M., Calabrò, G., Malekmohammadi, H., Sfarra, S., Ricci, M., Pelosi, C.: 'Development of integrated innovative techniques for paintings examination: the case studies of The Resurrection of Christ attributed to Andrea Mantegna and the Crucifixion of Viterbo attributed to Michelangelo's workshop', Journal of Cultural Heritage, 2019, 40, pp. 1-16.

[62] Tornari, V., Andrianakis, M., Chaban, A., Kosma, K.: 'Heat transfer effects on defect boundaries captured by digital holographic interferometry and infrared thermography workstation: an overview on experimental results', Experimental Techniques, 2020, 44(1), pp. 59-74.

[63] S. Eyssautier-Chuine, K. Mouhoubi, F. Reffuveille, J.L. Bodnar: Thermographic imaging for early detection of biocolonization on buildings, March 2020, Building Research and Information

[64] Eyssautier-Chuine, S., Mouhoubi, K., Reffluveille, F., \& Bodnar, J. L. (2019, July). Early detection of biofilm development on stone monuments thanks to pulsed IRT and SVD. In Optics for Arts, Architecture, and Archaeology VII (Vol. 11058, p. 110581H). International Society for Optics and Photonics.

[65] Mouhoubi, K., Bodnar, J. L., Vallet, J. M., \& Detalle, V. (2019, July). Follow-up of restoration of works of art of the patrimony by infrared thermography. In Optics for Arts, Architecture, and Archaeology VII (Vol. 11058, p. 110581E). International Society for Optics and Photonics.

[66] Mouhoubi, K., Detalle, V., Vallet, J. M., \& Bodnar, J. L. (2019). Improvement of the Non-Destructive Testing of Heritage Mural Paintings Using Stimulated Infrared Thermography and Frequency Image Processing. Journal of Imaging, 5(9), 72.

[67] Mouhoubi, K., Bodnar, J. L., Vallet, J. M., \& Detalle, V. (2019, July). Stimulated infrared thermography application to the conservation of heritage wall paintings: interest of a material and software combined approach. In Optics for Arts, Architecture, and Archaeology VII (Vol. 11058, p. 110580H). International Society for Optics and Photonics.

[68] Chahine, N., Mouhoubi, K., Bodnar, J. L., Toumi, Y., Millet, P., Benmarouane, A., \& Harakeh, S. (2019, June). The evolution of the mechanical properties of orthodontic arches by stimulated infrared thermography. In Optical Methods for Inspection, Characterization, and Imaging of Biomaterials IV (Vol. 11060, p. 110600K). International Society for Optics and Photonics.

[69] Thomachot-Schneider, C., Vázquez, P., Gommeaux, M., Lelarge, N., Conreux, A., Drothière, X., ... \& Bodnar, J. L. (2019). Thermal response of building stones contaminated with salts. Construction and Building Materials, 226, 331-344.

[70] Vázquez, P., Thomachot-Schneider, C., Mouhoubi, K., Bodnar, J. L., Avdelidis, N. P., Charles, D., \& Benavente, D. (2018). Sodium sulfate crystallisation monitoring using IR thermography. Infrared Physics \& Technology, 89, 231-241.

[71] Giovannacci, D., Brissaud, D., Mertz, J. D., Mouhoubi, K., \& Bodnar, J. L. (2017, July). Nonintrusive tools to detect salts contamination in masonry: case study of Fontaine-Chaalis church. In Optics for Arts, Architecture, and Archaeology VI (Vol. 10331, p. 1033103). International Society for Optics and Photonics. 